\title{
LA EMINENCIA DEL DETALLE "DISCIPLINARIO" EN EL PURÉN INDÓMITO, MARTÍN RIVAS Y EL MATADERO'
}

The eminence of "disciplinary" detail in Purén Indómito, Martín Rivas and El Matadero

Para los filósofos de la trasgresión

\author{
Mario Rodríguez Fernández* \\ José Manuel Rodríguez**
}

Resumen

Proponemos que ciertos “detalles” (la catálisis, según Barthes) revelan la presencia del poder disciplinario en la esfera del relato moderno. Iniciamos el análisis a partir de algunas unidades descriptivas del Purén Indómito, a las que consideramos antecedentes directos de esa revelación, y concluimos con la novela Martín Rivas y el cuento El matadero. El texto colonial da cuenta detallada de la vida cotidiana en el reino de Chile, cuenta que expresa las estrategias del poder de soberanía, mientras que en los relatos modernos relevará la presencia del poder disciplinario. Así, la presencia de detalles dramáticos en el Purén obedece a lograr la intervención jurídica-moral del monarca en el reino. En cambio, a partir del realismo esos detalles muestran el actuar de los cuerpos a someter y disciplinar, tal y como ocurre en Martín Rivas y El matadero. La estrategia narrativa será entonces sacar a la luz los detalles de las costumbres retrógradas, bárbaras, sucias, de la sociedad latinoamericana para disciplinarlas, limpiarlas y conseguir, así, naciones modernas y productivas.

Palabras clave: Panóptico, realismo, detalle-disciplinario, catálisis, poder, estrategias.

Abstract

Our proposition is that certain "details" (catalysis, according to Barthes) reveal the presence of disciplinary power in the sphere of modern fiction. Our analysis starts with some of the descriptive units of Purén Indómito, which we consider to be a direct precedent for this revelation, and we conclude with the novella, Martín Rivas, and the short story, El matadero. The text dating from the colonial period gives a detailed account of daily life in the kingdom of Chile, describing the strategies of the sovereign power, while the modern stories highlight the presence of disciplinary power. Thus, the purpose of the dramatic details recounted in Purén is to ensure the legal-moral intervention of the monarch in the kingdom. In realist works, on the other hand, these details show the actions of organisations to subject and discipline the people, just as it occurs in Martín Rivas and El matadero. In this case, the narrative strategy is to exhibit the details of the foul, barbarous, reactionary customs of Latin American societies in order to discipline and purify them, and thus transform them into modern, productive nations.

Key words: Panoptic, realism, disciplinary-detail, catalysis, power, strategies.

\footnotetext{
${ }^{1}$ Este artículo se escribió en el marco del Proyecto Fondecyt $\mathrm{N}^{\circ}$ 1121091: "De la aceptación a la resistencia: una anatomía del detalle disciplinario en la narrativa latinoamericana de los siglos XIX y XX". Los autores agradecen el apoyo esencial de Fondecyt para el desarrollo de su investigación.
} 
La inquietud suscitada por la lectura de algunas octavas del poema épico chileno Purén Indómito y la posibilidad de vincularlas con ciertas descripciones anotadas por los narradores de Martín Rivas y El matadero, originan estos escritos. La línea de unión, la inquietante línea de unión encontrada, es la presencia de una serie de sugerentes "detalles". Así, determinadas octavas del poema colonial incluyen pormenores absolutamente impropios del discurso épico, por cuanto refieren la presencia de lo cotidiano despojado de toda fabulación y heroísmo. Sabemos que la mayoría, sino todas, de las acciones de la épica están signadas por lo "grandioso", por lo notable. Tal y como las acciones de Eneas referidas por la Eneida o de Héctor anotadas en la Ilíada. Todas ellas se abocan a mostrar la grandeza del héroe, sus virtudes guerreras y "morales". En cambio en el poema épico colonial surgen descripciones que trastornan este principio. Un ejemplo lo encontramos en las palabras dedicadas a un guerrero, y violador de mujeres, del bando de los purenes, leemos: "los labios se le pegan con el sarro" (Arias de Saavedra, 160). Se trata de un verso contrastante con los del clásico poema épico renacentista La Araucana que describe a los mismos guerreros como: "bien formados los cuerpos y crecidos; / espaldas grandes, pechos levantados" (16). La diferencia entre ambos textos nos permite revelar un sensible rebajamiento de la fabulación, entendida como lo digno de ser cantado, en el Purén Indómito respecto de La Araucana, bello libro que se inclina por resaltar el valor, los hechos, las proezas, cosas notables, "temerarias empresas memorables" (Ercilla, 12). Cosas todas traspasadas por la gloria. Los labios pegados con el sarro, (más bien se refieren a lo indigno, o utilizando la nomenclatura usada por Foucault, en La vida de los hombres infames, a lo "infame", lo que carece de fama y no valía, por consiguiente, la pena contarlo: "Durante mucho tiempo, en la sociedad occidental, la vida de todos los días no ha podido acceder al discurso más que atravesada y transfigurada por lo fabuloso; era necesario que saliese de sí misma mediante el heroísmo, las proezas, las aventuras, la providencia y la gracia, o, eventualmente el crimen; era preciso que estuviese marcada por un toque de imposibilidad. Entonces esa vida se convertía en algo decible; lo que la colocaba en una situación inaccesible le permitía al mismo tiempo funcionar como lección y ejemplo. Cuanto más se salía de lo ordinario la narración, mayor fuerza cobraba para hechizar o persuadir" (136). Luego, de acuerdo con el autor, en el siglo XVII se comienza a producir un cambio en el horizonte con la aparición de las disciplinas en la sociedad moderna. Ellas construyen un dispositivo que obliga a presentarse a lo "ínfimo", lo que estaba excluido no por pequeño, sino porque al no estar traspasado por lo fabuloso no merece ninguna gloria, y por lo tanto, corresponde a lo "infame". La finalidad del imperativo es sacar a la luz la parte más oscura de la sociedad, casi siempre asentada en los detalles más ínfimos, que debe entenderse como lo desvergonzado o las desvergüenzas cotidianas, para controlar, disciplinar al sujeto. El dispositivo constituye una suerte de ética inmanente del discurso literario de 
Occidente y funda el sentido moderno de él: "Más que una forma específica, más que una relación esencial a la forma, es esta imposición, iba a decir esta moral, lo que la caracteriza"... (a la literatura moderna)...y la conduce hasta nosotros en su inmenso movimiento, la obligación de decir los más comunes secretos" (1990:137).

A pesar de que Purén Indómito es un texto épico colonial del siglo XVII, y como tal no podría ser considerado parte de la literatura moderna, que es la clase de ficción que nos interesa, lo incluimos en el análisis para mostrar cómo funciona el poder disciplinario en contraste con el que lo antecede, el de soberanía, en el que se incluye el Purén, y cómo a finales del siglo XVII esta forma del poder empieza a entrar en crisis. Tanto la inclusión, la comparación como el proceso de cambio, lo pensamos siempre en relación con los detalles. Es la fascinación por los detalles, muchas veces superfluos, y la inclinación de mostrar mediante ellos lo más oculto, lo que cuesta más trabajo decir, porque a menudo es lo prohibido y escandaloso lo que aproxima el Purén a esa moral, a ese imperativo propio de la literatura moderna de contar una ficción oscura, hasta entonces proscrita. A propósito de esa fascinación por el detalle, citamos unas páginas del Vigilar y castigar de Foucault. Este, como es su costumbre, cita allí a un obscuro personaje, el mariscal Mauricio de Sajonia, importante general de los ejércitos de Luis XIV, quien alguna vez afirmó: "aunque quienes se ocupan de los detalles son consideradas personas limitadas, me parece, sin embargo, que este aspecto es esencial porque es el fundamento, y porque es imposible de levantar ningún edificio ni establecer método alguno sin contar con sus principios. No basta con tener afición a la arquitectura. Hay que conocer el corte de las piedras" (143). A partir de estas palabras, el filósofo escribe: "de este corte de piedras se podría escribir toda una historia de la racionalización utilitaria del detalle en la contabilidad moral y el control político (143). Ahora, y en relación con la literatura, no negamos que el detalle, la catálisis en términos de Barthes, ha existido desde siempre en tanto elemento sustantivo de la narrativa. Basta pensar en las palabras pronunciadas por Nabokov durante una clase de sus célebres cursos de literatura dictados en Cornell University: "Hay que acariciar los detalles de los clásicos, los maravillosos detalles que constituyen la esencia de la narración" (16). Ello es cierto, pero no lo es menos, y esta es nuestra tesis, que será solamente en la narrativa desarrollada en el seno de las sociedades disciplinarias, el lugar donde el poder se ha alojado en los detalles.

Anteriormente, en la época clásica, al poder le interesaba la totalidad del sujeto, en especial el cuerpo del sujeto como una entidad completa que no se podía parcelar. Por ejemplo, en los versos ya citados de La Araucana se habla de cuerpos bien formados, de los cuales las espaldas y pechos grandes y levantados no son parcelaciones, sino que forman parte de una totalidad humana propia del mito épico, la del guerrero poderoso, del héroe hecho para el 
combate. Queremos decir que el héroe necesariamente debe tener así las espaldas y el pecho (no se los concibe enjutos), por lo que no son meros detalles, sino la reiteración de una figura completa. Esta reiteración cumple un rol fundamental en la trama del poema de Ercilla, ya que representa el énfasis en la necesaria paridad bélica de los contrincantes. En cambio, "los labios pegados con el sarro" que aparecen en el Purén no inciden en la capacidad guerrera de los indios; ellos con o sin sarro en los dientes pueden luchar y cometer barbaridades. Es, pues, un detalle superfluo, distinto al de las espaldas y pechos fuertes necesarios en el combate cuerpo a cuerpo. El detalle superfluo nos indica una preocupación fundamental del poder disciplinario: el indispensable cuidado en la limpieza del cuerpo. Además la suciedad, propia de los indisciplinados, forma sistema con la desvergüenza de los violadores, como veremos. Es dable que hombres sucios cometan acciones "sucias".

Foucault afirma que las disciplinas trabajan para conseguir "cuerpos dóciles y útiles" (2002:211); nosotros añadimos a la luz del relato hispanoamericano otro registro: el de limpios. No hay productividad sin limpieza; tal vez sí puede haber docilidad. En todo caso, los textos que analizamos conceden una prioridad esencial a la limpieza del cuerpo, llegándola a considerar metonimia de una época histórica o clase social.

Entonces, y en este muy específico campo de estudio, la catálisis ya no es un "relleno", sino que cumple una función en el texto y a esa función la podemos llamar disciplinaria.

Leído desde esa perspectiva, consideramos a Purén como uno de los primeros textos coloniales que introducen los detalles de la vida cotidiana en la literatura chilena, y que esa introducción, aparentemente, se integra al "gran sistema de coacción" que en Occidente ha obligado a lo cotidiano a pasar al orden del discurso. Purén, como texto literario, ocupa en este proceso un lugar especial al comprometerse a narrar en su práctica discursiva lo más indecible, lo peor, lo más intolerable, lo desvergonzado. Ello queda en evidencia en muchas partes del poema. Seleccionamos un par de ejemplos. El primero se refiere a las tropelías indígenas ocurridas durante la destrucción de Nueva Imperial:

Estaban a una virgen tres violando

En público, sin duelo ni vergüenza

Y la noble doncella dando gritos

Ambas manos ligadas con su trenza (Estrofa, 1526).

Aparte de la violencia y escándalo de la acción, queremos destacar el detalle "infame" de las manos atadas con la propia trenza de la niña. Para mostrar el carácter desvergonzado de la escena bastaban tal vez los gritos de la doncella, añadir el detalle de la trenza como atadura, muestra la fuerza de un dispositivo de coacción moral que obliga a ir más allá de los límites para narrar lo más escandaloso brutal y patético. Pero para los efectos del poder el 
escándalo no es lo más importante. La trenza es un signo del cuidado del cuerpo que separa a las españolas de las indias. Estas últimas usan el cabello suelto, destrenzado, evidenciando una práctica corporal descuidada, práctica que está de acuerdo con sus vestiduras "cortas y groseras".

El otro episodio, muy distinto en su trama, es el de una yunta de bueyes que el capitán Serrano manda a arrebatar a un indio respetable y amigo de los españoles. Cuando los "purenes" derrotan a las huestes hispanas y el capitán debe huir y esconderse de los indios, socarronamente estos empiezan a preguntar: "¿Dónde está Serranito, por qué no sale a ver los lindos bueyecitos que le trae Quilacán?” (Estrofa, 1156). Del detalle disciplinario corporal hemos pasado a otro detalle: el robo de una yunta de bueyes que nos indica el desapego real a las normas disciplinarias. Queda en evidencia que en las prácticas cotidianas de la guerra la moral cristiana es sobrepasada constantemente.

Según lo expuesto, nos encontramos frente a una situación contradictoria: el Purén Indómito es un texto colonial en el cual aparentemente están presentes los dispositivos de coacción que funcionan en la representación de lo cotidiano propios de la literatura moderna. Aumenta la contradicción en cuanto la estructura de poder en que se cobija el poema épico es la propia del poder monárquico, estructura distinta del poder disciplinario que organiza la sociedad moderna.

¿Cuál podría ser la explicación? Ensayaremos no solo una, sino varias.

Una primera respuesta a nuestra interrogante la podríamos encontrar en el texto de Erwin Rodhe, La novela griega y sus precursores (1876), donde afirma que la desagregación de los géneros elevados contribuye a la formación de la novela,e lucha contra la épica y la derrota, pues pertenece a una categoría absolutamente diferente, su aparición no ocurre por evolución, sino por generación de lo nuevo. El texto de Arias de Saavedra podría situarse en un punto de inflexión donde ya se "desagrega" la épica y su lugar es ocupado por una nueva forma literaria: la novela. Nosotros agregamos que en ese combate, en el caso específico que tratamos, no solo está presente una cuestión de géneros, sino también de la relación de la literatura con el poder. Así, el Purén Indómito revelaría en su interior la crisis del poder monárquico y el surgimiento de las primeras formas incipientes del poder disciplinario. La prueba es que el héroe triunfante del poema épico, el gobernador Quiñones, antes que un guerrero heroico es un agente que repara, que ordena, que reorganiza el reino de Chile, imponiendo la moral cristiana del cuerpo, negada y excluida, según el poema, de las prácticas coloniales del siglo XVII. Acciones bastante lejanas a las desarrolladas por figura consular de la épica cristiana: el Cid, quien, más que nada, es un buen vasallo y un guerrero heroico. En cambio, para el autor del Purén la acción guerrera es secundaria, lo importante es la moral que se impone a los cuerpos. Quiñones aplica un "salutífero antídoto" a la "contagiosa 
pestilencia chilena". Su empresa será reformar la vida de los habitantes del reino, combatiendo las malas costumbres y exaltando las virtudes:

Reformador de vidas y costumbres

Por quien brotaron las virtudes lumbres

(Purén Indómito estrofa 1615).

Esta sentencia nos permite establecer una relación directa entre el poema con la novela moderna chilena, pues autores como Lastarria y Blest Gana proponen como una función de la literatura su intención de reformar la sociedad apelando, como en Martín Rivas, a "las nobles virtudes del corazón" ("virtudes lumbres"). Y no solo a ellas, pues Martín Rivas, el personaje, cumple una función en la sociedad muy similar a la cumplida por Quiñones. Ya Jaime Concha observa que "Martín es siempre agente de afinidades electivas que pasan por claras coordenadas de clase. Separa lo socialmente heterogéneo, une lo homogéneo socialmente" (1992:XXXII). En nuestros términos, podríamos anotar que Rivas funciona como un agente disciplinario dentro del relato. Ahora, la diferencia fundamental entre ambos textos, aparte de las propias entre el género épico y el novelesco, estriba en que si Purén apela a la noción cristiana del poder, la pastoral, los autores del realismo nacional lo hacen bajo la impronta de otro ideario social e ideológico, la del panoptismo, una máquina de visión capaz de transparentar la sociedad. No estamos inventando nada, la vasta influencia en los forjadores de la independencia y del estado nacional de la ideas del Jeremías Bentham, inventor de la máquina disciplinaria que llamó panóptico, está documentada (Neira 2004:285-313). En esta línea, recurriendo al análisis y a las proposiciones de Foucault sobre la posibilidad de extender las ideas de Bentham más allá de la esfera carcelaria, podríamos decir que los relatos del realismo chileno, y latinoamericano, presentan una estructura panóptica que proyecta el mecanismo como "una manera de definir las relaciones del poder en la vida cotidiana de los hombres" (2002:208).

Desde ahí afirmamos que la novela realista está determinada en el plano de los contenidos por la irrupción de la vida cotidiana en las historias narradas bajo el imperativo de contar no solo los hechos más comunes, sino los más ínfimos, los hechos "infames", es decir, no solo los detalles que revelan desorden, falta de higiene, etc., sino también los hechos carentes de fama, hechos que se sumergen en la marea de la historia. En el nivel de la estructura a la novela realista la define un diseño panóptico en el cual el narrador omnisciente asume el mismo rol del gran vigilante descrito por Bentham, a propósito de su invento carcelario. Podríamos decir que en el lineamiento de toda novela realista hay una pequeña prisión. La prisión no solo hay que entenderla bajo la idea del encierro, ya que el panóptico también puede ser utilizado como laboratorio, como una máquina disciplinaria capaz de ensayar experiencias que modifiquen el comportamiento de los individuos para encauzar 
o modificar su conducta: "el Panóptico es un lugar privilegiado para hacer posible la experimentación sobre los hombres, y para analizar con toda certidumbre las transformaciones que se pueden obtener en ellos" (2002:207).

¿No suena próxima esta definición a las formas propias de la llamada novela de aprendizaje? ¿Y, también, a las de la novela experimental del naturalismo?

Dejando aparte la semejanza y correspondencia y volviendo al Purén Indómito, es indudable que el panoptismo en sus dos variantes estructurales no funciona en el poema; sin embargo, sí opera la irrupción de la vida cotidiana, la relación de los lugares comunes marcados por los detalles más ínfimos, los sin fama. Lo inquietante de ello es que su "infamia" se produce por la recurrencia, como decíamos, del detalle brutal o insidioso, mucho más del que logra alcanzar la novela realista. Martín Rivas, por ejemplo, nunca toca la brutalidad con que se presentan los detalles en las descripciones del Purén. Los "humores" del cuerpo están prescritos, no hay mal aliento en la boca de los personajes ni "sarro en los labios", menos en los burgueses. Cuando aparece este universo ínfimo el narrador se detiene al borde de él, resistiéndose a incorporarlo al texto: "Dar una idea de aquella criada, tipo de la sirviente de casa pobre, con su traje sucio y raído y su fuerte olor a cocina, sería martirizar la atención del lector. Hay figuras que la pluma se resiste a pintar, prefiriendo dejar su producción al pincel de algún artista: allí está en prueba el "niño mendigo", de Murillo, cuya descripción no tendría nada de pintoresco ni "agradable" (77-78). Lo desagradable, lo sucio y raído quedan al margen de la "limpieza" que predomina en el universo narrado. Nuevamente el detalle aparece como el dispositivo fundamental. Esta lista circunstanciada y minuciosa de rasgos (traje sucio y raído, olor a cocina) que definen el aspecto de la criada nos proporciona aquellos efectos de realidad "tan necesarias en la construcción del mundo novelesco", como los llama Barthes. Y no solo eso, el detalle nos va a permitir desarrollar una relación inédita, en el caso de Blest Gana, entre "limpieza" y modernidad, y en el caso de Echeverría, otra no menos interesante sobre "suciedad" y colonia. A partir de estas relaciones nos podemos dar cuenta que la representación de la vida cotidiana exhibida en toda su crudeza, los indios huelen mal, los españoles no lo hacen mejor; los primeros son borrachos contumaces, los segundos grandes fornicadores, obedece a la necesidad imperiosa de lograr una intervención jurídica-moral del monarca y no a una estrategia disciplinaria. Tal vez haya en el texto colonial una libertad mucho mayor en la representación de lo "infame" que en el texto moderno. Se necesita conmover al poder real para que actúe. En el relato moderno no hay apelación a un poder central, único, sino a múltiples prescripciones, normas cotidianas y reglamentos que facilitan la docilidad de los cuerpos. 
Por ello nos inquietó la lectura del Purén. Suponíamos que el poder monárquico o de soberanía era más rígido que el poder disciplinario. Creíamos que la malla discursiva, en la relación poder-saber y discurso, estaba más apretada, era más represiva, en la dimensión del poder de soberanía y un poco más abierta en el disciplinario. Sin embargo, la realidad representada, o mejor dicho, imaginada en los textos descritos nos indicaba que no era así, más bien funcionaba al revés. Pero ahora podemos decir que la diferencia está en el detalle. Que su brutalidad, su "infamia", cumplen funciones distintas en el texto colonial y el moderno. En el primero, el detallismo, dramático, en muchos casos, está destinado a conmover al soberano para poner en funcionamiento su formidable, pero pesado mecanismo de poder. En el segundo, conseguir mediante un disciplinamiento impersonal un modo de ordenar las relaciones cotidianas de poder en una sociedad. Pero si nos inquietó, también nos confirmó la tesis central que nos guía: son los detalles en las descripciones, en los movimientos y actitudes de los personajes donde hace su irrupción lo común, lo más ínfimo, lo infame. Y lo más importante, es que en estos detalles es donde el poder hace su presa. Por debajo de los grandes discursos jurídico-sociales de la modernidad que aseguran la libertad e igualdad, funciona esta "microfísica del poder" que, constantemente y en forma silenciosa, no se cansa de negar esos principios universales, apretando la mano en el universo ínfimo de los gestos, de las posturas corporales, en los modos de vestirse, peinarse, en las maneras de caminar, de mirar, etc. Todos los detalles que constituyen lo ordinario son registrados en la novela y no solo para que queden en un archivo, sino para operar sobre ellos catalogándolos en modernos (civilizados) y atrasados (bárbaros) en el caso de la narrativa hispanoamericana del siglo XIX. Los primeros aseguran el orden social basado en la docilidad y productividad de los cuerpos; los atrasados hay que corregirlos para conservar ese orden. Cuando no se puede lograr la docilidad de los cuerpos, por su naturaleza contumaz, el relato realista los elimina brutalmente, o, en forma más suave, los excluye de la "ciudad" y los encierra en "casas correccionales" (hospitales, cuarteles, manicomios, escuelas especiales, etc., y en la ficción panóptica) para enderezar sus comportamientos torcidos. Desde ahí se produce el nacimiento de variados discursos: el clínico o médico, el policial, el pedagógico correccional, el judicial, el psiquiátrico y el ficcional de la novela panóptica, que determinan la operatividad del poder a partir del siglo XVII. Anterior a este siglo, la figura del rey impedía, o en el mejor de los casos, opacaba la presencia de tales discursos en la vida cotidiana. Como escribe Foucault: "Este discurso de lo cotidiano, en su forma primigénica, estaba totalmente vertido hacia el rey; se dirigía a él, se filtraba en los grandes rituales ceremoniosos del poder y debía adoptar su forma de revestir sus signos. Lo banal no podía ser dicho, escrito o descrito, observado, organizado y valorado más que en una relación de poder que estaba 
obsesionada por la figura del rey, por su poder real y por el fantasma de su poderío" (1990:133). Esto es, lo destacamos, exactamente lo que sucede en el Purén. Continúa Foucault en el mismo texto: "La oreja de Dios era una pequeña máquina muy elemental si la comparamos con esta. Qué fácil sería sin duda desmantelar el poder si este se ocupase simplemente de vigilar, espiar, sorprender, prohibir, castigar; pero no es simplemente un ojo ni una oreja: incita, suscita, produce, obliga a actuar y hablar" (136). La afirmación que el poder incita a hablar explica, por otra parte, el desparpajo, la vehemencia insistente del autor del Purén en describir los detalles más bajos, reprobables y con frecuencia escandalosos de las prácticas coloniales.

Estos dispositivos y los posteriores del poder disciplinario no solo han sido importantes para los nuevos saberes ya enunciados - los del discurso policial, jurídico, etc.- , sino que también han influido decisivamente en el discurso literario. No significa que el Purén Indómito, y textos similares en su intención discursiva como Cautiverio Feliz (2002) o, muy especialmente, El carnero (1992), sean los antecedentes de la novela moderna, sino que a fines del siglo XVII y todo el XVIII las relaciones del discurso con el poder, la vida cotidiana y la verdad se entrelazaron de un modo distinto y novedoso al del período clásico, dando origen al discurso literario de la modernidad. Las relaciones entre el discurso, el poder y aquello que se considera como verdad en un momento histórico determinado han sido tratadas por la filosofía y la crítica. En específica relación con la literatura, recordamos a Bajtín, quien llega a considerar que el discurso literario está traspasado por la ideología y la lucha social. Él afirma: "las categorías estilísticas... fueron generadas y formalizadas por las fuerzas históricamente actuales del devenir verbal-ideológico de ciertos grupos sociales, y constituyeron la expresión teórica de estas fuerzas activas que creaban la vida del lenguaje. Estas son las fuerzas de la unificación y centralización del mundo verbal-ideológico" (1986:95-96). La diferencia que planteamos a lo afirmado por el teórico ruso radica en que, para nosotros, las fuerzas no se marcan a nivel de los grandes relatos, de los grandes discursos, sino en el nivel microfísico. Para el caso, al nivel de los detalles más ínfimos de la narración. Tan ínfimos que su presencia pareciera no influir, de hecho no lo hace, ni siquiera, en la diégesis. En este punto podemos decir que creemos ver resuelta una de las inquietudes que nos produjo la lectura del Purén, como asimismo la aparente paradoja de encontrar en un texto colonial formas propias del poder correspondiente a la modernidad.

De todas maneras nos permitimos reiterar la importancia del detalle, del peso fundamental que tienen estos aspectos ínfimos de la vida cotidiana en las nuevas relaciones del discurso literario con el poder. Puntualmente en la novela realista los detalles, aparte de cumplir la función, observada por Barthes, de 
producir "efectos de realidad" (21), son las formas "insidiosas", que actúan por debajo, las que elige el poder para disciplinar la sociedad.

Desarrollando las relaciones que propusimos, podemos construir dos equivalencias "limpieza" = "modernidad" / "suciedad" = "colonia", Rivas?

¿Cuál sería el sentido de la ecuación limpieza $=$ modernidad en Martín

Según lo dicho, aparece como un factor histórico general la necesidad de modernizar la sociedad mediante una purificación simbólica, de limpieza, que eliminase las huellas del poder colonizador. La "purificación" se realiza fundamentalmente en los niveles que corresponden a las descripciones que acompañan la historia narrada y en algunas afirmaciones extradiegéticas del narrador de la novela, leemos: "No es Santiago en ese día la digna hija de los serios varones que la fundaron. Pierde entonces la afectada gravedad española que durante todo el año la caracteriza" (237). Claramente la afectada gravedad es una "huella" persistente de la colonización, borrada ocasionalmente por el jolgorio y alegría patriótica que desatan las fiestas de la Independencia. La "limpieza" se refuerza en un hecho esencial para la novela: la sociedad chilena debe instaurar rasgos de diferenciación respecto de la sociedad colonial. El regocijo patriótico frente a la gravedad colonial es una evidente forma de diferenciación.

Esta operatividad del detalle compone una suerte de anatomía, que está presente en todas las descripciones del texto, las que tienden a organizarse como un reconocimiento positivo del cambio que produce la "moderna usanza" enfrentada a las "viejas costumbres". El cambio consiste, fundamentalmente, en un disciplinamiento de la vida cotidiana por medio de una serie lógica simple:

$$
\text { individuo limpio } \rightarrow \text { nación limpia } \rightarrow \text { nación moderna. }
$$

Martín Rivas narra el actuar de un sujeto que metonímicamente indica el modo en que debe disciplinarse, limpiarse, la nación para alcanzar la modernidad. En esta actuación, las grandes articulaciones del relato no son las más importantes para observar cómo funciona el poder, son los detalles los que importan. La disciplina a la que está sometida la clase burguesa, a la que pertenece Martín, se expresa primordialmente en el detalle de su limpieza. Basta para comprobarlo la descripción de otro personaje, Dámaso Encina: "Su traje negro, su cuello bien almidonado, el lustre de sus botas de becerro, indicaban al hombre metódico, que somete su persona, como su vida, a reglas invariables... perfectamente afeitado y peinado, el rostro y el pelo de aquel hombre manifestaba que el aseo era una de sus reglas de conducta" (17). Queremos destacar el detalle del pelo del disciplinado burgués Encina y compararlo con el peinado de Amador Molina, integrante de otra clase social, la de "mediopelo: 
"Mira, mira — dijo San Luis, asiendo el brazo de Martín- Allí va Amador, el hermano; ese que lleva un vaso de ponche, llamado en estas reuniones chincolito. ¿No encuentras que Amador es soberbio en su especie? Ese chaleco de raso blanco, bordado de colores por alguna querida prolija, es de un mérito elocuentísimo. La corbata tiene dos listas lacres que dan un colorido especial a su persona y el pelo encrespado, como el de un ángel de procesión, tiene la muda elocuencia del más hábil pincel porque caracteriza perfectamente el personaje" (78).

Por contraposición al perfecto peinado de don Dámaso, Amador ofrece uno aparatoso, el pelo "encrespado de un ángel de procesión, muy difícil de mantener limpio. Pero bajo estas minucias diferenciadoras no buscamos solamente un sentido, sino, además, una precaución: la coherencia de una táctica propia de la microfísica del poder. "Perfectamente peinado" significa orden y pulcritud, pero como precaución, una necesidad táctica de ahorrar energía y tiempo, despilfarrada en la confección y el aseo de un complicado peinado. Una de las primeras exigencias del poder disciplinario es el de no malgastar el tiempo en el trabajo y en el cuidado del cuerpo. Para ello es indispensable una rutina, una repetición de los mismos gestos, a fin de ajustar el cuerpo a un imperativo temporal: actuar tal y como actúa un soldado que al levantarse en el cuartel ejecuta actos preestablecidos de antemano por el reglamento, no desperdiciando así ni tiempo ni energía. Por su parte, quien sí los derrocha es Amador, pues pelo encrespado exigiría, para alisarlo, renovadas maniobras diarias. En rigor, lo que hacen las disciplinas es extraer del tiempo más instantes disponibles para conseguir más rapidez y eficacia. Repetir la misma operación aumenta la celeridad de ella. La comparación con los peinados de los ángeles de procesión introduce una mención disrruptora con la religiosidad de las fiestas coloniales. Creemos, también, que existe un matiz racista en el pelo encrespado cuya forma podría provenir del pelo "moteado" de la raza negra. Por último, la oposición entre liso y encrespado, con el privilegio del primer término, revela la opción del poder por la docilidad, que implica economía del tiempo y limpieza en la funcionalidad de los cuerpos disciplinados.

En otros relatos modernos, como en el extraordinario cuento El matadero (2006) de Esteban Echeverría, la "anatomía del detalle", que apunta a la ecuación limpieza $=$ modernidad, es mucho más expresiva que en Martín Rivas $\mathrm{y}$, adicionalmente, envuelve algunas equivalencias más complejas a las presentes en la novela de Blest Gana. El contexto histórico-social argentino en el cual se inserta El matadero, escrito varios años antes que Martín Rivas, podría explicar las diferencias en la clave política del detalle que rastreamos. La ecuación limpieza = modernidad es paralela en el texto de Echeverría a la de "suciedad" = colonia de un modo más evidente que en Blest Gana. El narrador hace claramente visible, en el inicio de su relato, la presencia de las huellas 
coloniales en la Argentina postindependencia: "A pesar de que la mía es historia, no la empezaré por el arca de Noé y la genealogía de sus ascendientes como acostumbraban hacerlo los antiguos historiadores españoles de América, que deben ser nuestros prototipos. Tengo muchas razones para no seguir, ejemplo, las que callo por no ser difusos. Diré solamente que los sucesos de mi narración pasaban por los años de Cristo de $183 \ldots$ Estábamos, a más, en cuaresma, época en que escasea la carne en Buenos Aires, porque la Iglesia, adoptando el precepto de Epicteto, sustiene, abstiene (sufre, obstante), ordena, vigila y abstinencia a los estómagos de los fieles a causa de que la carne es pecaminosa, y como dice el proverbio, busca la carne. Y como en la Iglesia tiene ab initio y por delegación directa de Dios el imperio inmaterial sobre las conciencias y los estómagos que en manera alguna pertenecen al individuo, nada más justo y racional que vede lo malo" (27). La ironía del párrafo parece provenir de la irritación que produce en el autor la presencia visible de los restos del orden colonial todavía enquistados en la historia oficial y en el seno de la Iglesia. Comenzado el relato podrá verse que a los factores de la historia y la Iglesia añade otro, en el que también se conserva el retardatorio orden colonial: las clases bajas, el pueblo mismo. El texto retrata las clases populares, puntualmente los personajes populares, como sujetos indisciplinados, indóciles y carentes de "limpieza". Así podemos notarlo en las palabras que siguen: "La perspectiva del matadero a la distancia era grotesca, llena de animación. Cuarenta y nueve reses estaban tendidas sobre sus cueros, y cerca de doscientas personas hollaban aquel suelo de lodo regado con la sangre de sus arterias. En torno de cada res resaltaba un grupo de figuras humanas de tez y raza distintas. La figura más prominente de cada grupo era el carnicero con el cuchillo en la mano, brazo y pecho desnudo, cabello largo y revuelto, camisa y chiripá y rostro embadurnado de sangre. A sus espalda se rebullían, caracoleando y siguiendo los movimientos, una comparsa de muchachos, de negras y mulatas achuradoras, cuya fealdad trasuntaba las arpías de la fábula, y entremezclados con ellas algunos enormes mastines olfatean... gruñendo se daban de tarascones por la presa" (34).

Empezaremos por el detalle del pelo. Si en Martín Rivas la notación de "encrespado" apuntaba a una persona ociosa incapaz de alisarse la cabellera para conseguir rapidez, eficacia y limpieza en su cuidado personal, en $E l$ matadero la cabellera es abiertamente larga y revuelta. Esta revoltura nos indica que no hay ninguna preocupación por la higiene ni el cuidado del cuerpo. Estamos frente a cuerpos indóciles, propios de la barbarie, como añadirá más adelante al narrador. Barbarie presente tanto en el cabello descuidado como en el rostro embadurnado de sangre, y la fealdad de muchachos, negras y mulatas. Lo sucio se une a la fealdad de las clases populares. Notable es contrastar el pelo del bárbaro con el pelo del joven unitario que cabalga casualmente cerca 
del matadero: "-Allí viene un unitario - y al oír tan significativa palabra toda aquella chusma se detuvo como herida de una impresión súbita - ¿No le ven la patilla en forma de U? No trae divisa en el fraque ni luto en el sombrero" (40). La patilla en forma de U envuelve toda una gama semiótica. En primer término, es un signo político, un arreglo de la barba que apunta al ideario del joven. Pertenecer a la facción unitaria, opuesta a la federación, es incluirse en una clase política burguesa, limpia, bella, culta, educada en París. Clase opuesta a la clase de los matarifes, de las mulatas, de los muchachones del matadero que componen la clase popular, mal hablada, mal vestida, sucia y fea. La patilla se transforma en poderoso signo social de superioridad de clase.

En segundo lugar, tal vez debería ser el primero, apunta a la forma en que opera el poder. Foucault muestra que desde la época clásica se desarrolla un descubrimiento "del cuerpo como objeto y blanco de poder" (2002:140). Cuerpo que se manipula para hacerlo útil, dócil, educado. A partir del siglo XVII el manejo del cuerpo sufre un cambio. Sigue siendo objeto de intereses imperiosos y apremiantes, sin embargo, hay algo nuevo: la escala de control. No estamos en el caso de tratar el cuerpo como si fuera una unidad indisociable, afirma, "sino de trabajarlo en sus partes, de ejercer sobre él una coerción débil, de asegurar presas al nivel mismo de la mecánica: movimientos, gestos, actitudes, rapidez; poder infinitesimal sobre el cuerpo activo" (2002:144). Luego, es evidente que el detalle de la patilla en U se incluye en ese trabajo por partes que hace el poder disciplinario, eludiendo la totalidad, porque es más fácil ejercer coerción sobre la minucia que sobre la amplitud corporal. Basta el recorte de las patillas para mostrar que estamos frente a un cuerpo sometido y "limpio", ejercitado en la disciplina. El pelo largo y revuelto del matarife indica todo lo contrario. Revuelto funciona como una precaución, una estrategia que apunta al comportamiento de una clase social: "a sus espalda rebullían, caracoleando y siguiendo los movimientos una comparsa de muchachos, de negras y mulatas achuradoras" (38). El pueblo es una comparsa heteróclita que rebulle y caracolea como una manada miserable. Frente a la revoltura del desorden popular, aparece el signo cuidado, estratificado, refulgente de la patilla. En la U está contenida buena parte de la semiosis social elaborada por la burguesía argentina del siglo XIX.

En estas minucias se aloja el poder disciplinario, desmintiendo, por abajo, los discursos del progresismo político, social, jurídico proclamado, entre otros, por el mismo Echeverría en El dogma socialista (1996), pues frente a las intenciones igualitarias proclamadas en el texto, se encuentran las minucias disciplinarias, alojadas en el discurso de la civilización, que hacen de ese mismo discurso igualitario un imposible.

El poder, insistimos, no funciona en lo alto, sino en las meticulosidades que definen cierto modo de adscripción política y detallada del cuerpo. En el 
detalle de la patilla recortada en U, contrastado con el descuido del cabello del matarife está la diferenciación clasista de la Argentina decimonónica emblematizada, por una parte, en el joven unitario de la clase burguesa y por otra, en el matarife que representa al populacho que apoya a Rosas. Desde la perspectiva de Sarmiento, correspondería a ese binarismo que recorre transversalmente la Argentina: civilización v/s barbarie. En esta línea, semióticamente las patillas del joven unitario se inscriben en la constelación de signos que rotan en el campo de la civilización, la burguesía y la modernidad. El pelo revuelto, en cambio, es la barbarie, el populacho inculto y la colonia

Describir estos pequeños ardides dotados de un gran poder de difusión (suponemos que la patilla es un signo que compromete a una clase social completa) implica estancarse en lo ínfimo, en lo pequeño, en lo menor. Y desde ahí surge el temor de no alcanzar nunca a agotar el estudio de lo infinitamente pequeño. Pero como afirma Foucault, "la disciplina es una anatomía política del detalle", una anatomía del "corte de las piedras" para levantar el edificio. Así, a partir del "corte de piedras", es decir, de la forma de la patilla y de la relevancia del pelo revuelto, se podría escribir toda una historia de Argentina. Especialmente de la patilla en U como una racionalización utilitaria del detalle en la contabilidad moral y el control político.

En conclusión, las referencias que hicimos al poema épico chileno del siglo XVII Purén Indómito nos permitieron advertir que la inclusión de la vida cotidiana despojada de la fabulación, de ese toque de imposibilidad de lo real, comienza sugestivamente con este poema que clausura la epopeya en Chile. La cotidianidad irrumpe mediante la descripción de minucias, de rasgos mínimos de los personajes y la vida social del Chile colonial. En la dinámica del poema, la parte que antecede a la llegada del "salutífero antídoto", el gobernador Quiñones y su esposa Grimanesa, es un registro de las "infamias" que suceden en el reino. Curiosamente este registro podría ser comparado con las llamadas lettres de cachet examinadas por Foucault en La vida de los hombres infames. Nos parece enfrentar aquí un tema a investigar porque las lettres, en cierto modo, podrían ser consideradas como antecedentes de la novela moderna, en lo que atañe a la incorporación de lo cotidiano. Aunque Foucault se apresura a aclarar que lo que le interesa de esos documentos es el anuncio de nuevas relaciones entre el poder, el discurso y la vida cotidiana. Notamos, también, en ellas la presencia de nuevas relaciones que se van a dar plenamente en la literatura moderna. Nosotros creemos que en la tradición literaria chilena, textos como Purén Indómito y Cautiverio Feliz, al introducir la minuciosa del detalle de la vida cotidiana, anuncian nuevas relaciones entre el poder, la verdad y lo cotidiano. Relaciones que la novela chilena del siglo XIX va a recoger y desarrollar. Claramente no hablamos de "protonovelas", ni de antecedentes del texto llamado novela, sino de nacientes relaciones otras entre poder y 
cotidianidad. Así, el sorprendente énfasis en la brutalidad y la desvergüenza de algunos detalles que presenta el Purén se puede explicar por el dispositivo construido por el poder de la soberanía en que se incluye el texto. El poder real incitaba a hablar para controlar el orden en sus colonias. En este punto recurrimos a la imagen de la gran oreja del rey propuesta por Foucault. De todos modos nos inquietó y sorprendió la brutalidad de algunos detalles, como el de "su propia trenza", con la que los indios amarraban las manos de la doncella que violaban. De aquí, al comparar este hablar desembozado con la pudibunda actitud del narrador de Martín Rivas, que se niega a describir la pobreza, fealdad y olor a comida de una criada y mucho menos la pasión sexual de Martín y Leonor, se genera una ecuación, ya anunciada, de una lógica simple: individuo limpio $=$ hogar limpio, que se continúa en otras ecuaciones que se desprenden de ello:

$$
\text { hogar limpio = nación limpia / nación limpia = nación moderna. }
$$

Lo interesante de esas equivalencias es que se producen a partir de esta "anatomía" del detalle que hemos propuesto. No se desprenden, por consiguiente, de las grandes intrigas, de los acontecimientos novelescos más importantes. Propusimos que la razón puede estar en que el poder disciplinario actúa en las minucias, allí hace su presa, sin interesarle demasiado los elevados discursos jurídicos, políticos y morales. Así, estos discursos pueden proclamar la libertad y la igualdad sin que se altere el campo del afán disciplinario que opera con un conjunto de reglamentos militares, escolares, hospitalarios y por procedimientos empíricos y reflexivos para controlar y corregir las operaciones del cuerpo. Mientras por arriba se habla de libertad, por abajo el poder disciplinario construye la invisible red que apresa el cuerpo, tal y como vimos más arriba en el caso de Echeverría.

Aunque no es esperable, es lógico que desde el punto de vista de la burguesía liberal en la que se incluyen estos autores modernos, la clave de todas las ecuaciones descritas esté fundada en la superioridad de su clase, "limpia" y disciplinada, sobre las clases populares, "sucias" y desordenadas. Así, Blest Gana anhela una limpieza disciplinaria de la sociedad chilena de mediados del siglo XIX proponiendo como ejemplo a Martín Rivas. Por su parte, El matadero exhibe la urgente necesidad de higienizar la Argentina y ello se lograría extirpando el foco "infeccioso" donde viven y reinan los matarifes, símbolo de la barbarie colonial, más que de la federación rosista. El peligro de que la infección se propague es una de las mayores preocupaciones del poder disciplinario.

Lo importante, insistimos, en Martín Rivas y El matadero es que tanto el disciplinamiento como su contrario están contenidos en los detalles "superfluos", "inútiles", no en las grandes articulaciones del relato. Que don 
Dámaso Encina esté "perfectamente peinado" no es un rasgo imprescindible para la marcha de la historia. En los términos utilizados por Barthes "parece responder a una suerte de lujo de la narración" (211). Lo mismo podría afirmarse de la cabellera revuelta del matarife en El matadero. A lo más, desde la perspectiva del teórico francés, se trataría de rellenos (catálisis) afectados de un valor funcional indirecto, en la medida que al sumarse, constituyen algún indicio de carácter o de atmósfera y "pueden ser así finalmente recuperados por la estructura" (212). Concordamos que esta misma carencia de significado en provecho del referente llega a ser el significado mismo del realismo, en cuanto produce un "efecto de realidad" que constituye parte esencial de la estética de las obras realistas, tal y como ocurre en Martín Rivas y El matadero. Pero el "efecto de realidad" no puede impedirnos ver al mecanismo del poder que funciona en él. Ver que el poder disciplinario opera sobre las partes del cuerpo, no en su totalidad. O visibilizar que alisar el pelo y peinarlo es una minucia, un gesto mínimo, una técnica insignificante, pero que consigue el fin supremo al que aspira el poder: disciplinar al sujeto. En la patilla en U del unitario y en el pelo domesticado de don Dámaso no sólo hay ese "efecto de realidad" del que habla Barthes, sino una precaución, un aviso que en los detalles está la presencia del poder disciplinario $\mathrm{y}$, consecuentemente, la temible lógica del panóptico.

Como sucede casi siempre en las ciencias humanas, el término de una investigación implica el inicio de otra sobre el mismo tema. El conocimiento en el campo de las humanidades parece estar entretejido de un modo distinto al de otras ciencias, como la física, por ejemplo, donde siempre se debe cerrar el experimento. Por ello el progreso del conocimiento se efectúa por acumulación. En las humanidades cada acontecimiento social, literario o artístico está ligado a otro de un modo tan íntimo que no hay corte posible. Cortar el "diálogo" es sinónimo de fracasar. En nuestro caso, la clausura es imposible a pesar que llegamos a proponer como conclusión un verdadero axioma:

individuo limpio: nación limpia / nación limpia: nación moderna.

Esa proposición axiomática que aparece clara y evidente en los textos analizados y circunscrita, por lo tanto, a una significación predominante, establece un diálogo con otros textos, se integra a una red discursiva que abre otras significaciones impensadas por su brutal contenido. Textos que tratan el mismo "detalle" de la "limpieza", como Facundo (2002) y Conflictos y armonías de las razas en América (1915), ambas de autoría de Domingo Faustino Sarmiento y contemporáneos de los relatos analizados, transforman la limpieza en una exclusión racista. "Limpiar" en el escritor argentino ya no solo significa disciplinar, sino como lo preanuncia El matadero, derechamente exterminar: "Puede ser muy injusto exterminar salvajes", escribe Sarmiento 
(1915:54), pero el progreso y la modernización de las nacientes repúblicas sudamericanas lo justifica y lo avala. Exterminar salvajes equivale a exterminar indios, negros, pobres, gente sucia, poblaciones no caucásicas. Nunca sospechamos que la "eminencia del detalle" nos llevaría a tan escandalosa conclusión para la atmósfera cultural en que nos movemos. Sin duda que estamos obligados a repensar la noción de "limpieza" en otro trabajo, que tal vez debe empezar con una reflexión que don Domingo Faustino escribe impávidamente: "América, en lugar de permanecer abandonada a los salvajes, incapaces de progreso, está ocupada hoy por la raza caucásica, la más perfecta, la más inteligente, la más bella y la más progresiva" (1915:75).

$$
\begin{array}{r}
\text { Universidad de Concepción* } \\
\text { Departamento de Español } \\
\text { Instituto de Lenguas } \\
\text { Barrio Universitarios/n, Concepción (Chile) } \\
\text { mariorod@udec.cl }
\end{array}
$$

Universidad de la Frontera**

Departamento de Lengua, Literatura y comunicación

Facultad de Ciencias Sociales y Humanidades

$2^{\circ}$ piso, Francisco Salazar 01145, Temuco (Chile)

jrodriguez@ufro.cl

\section{OBRAS CITADAS}

Arias de Saavedra, Diego. Purén Indómito. Biblioteca Nacional, Universidad de Concepción. Seminario de Filología Hispana. Santiago de Chile: Editorial La Noria: Santiago, 1984.

Bajtin, Mijaíl. Problemas literarios y estéticos: Editorial Arte y Literatura, Cuba, 1986.

Barthes, Roland. El efecto de realidad, en El susurro del lenguaje: Barcelona: Editorial Paidós, 1987:211ss.

Blest Gana, Alberto. Martín Rivas. Santiago: Editorial Gabriela Mistral, 1974.

Concha, Jaime. "Prólogo", en Blest Gana, Alberto. Martin Rivas. Caracas: Biblioteca Ayacucho, I y ss., 1992.

Foucault, Michel. Vigilar y castigar. Buenos Aires: Siglo XXI, 2002.

------ La vida de los hombres infames. Madrid: La Piqueta, 1990.

Echeverría, Esteban. "El matadero", en Antología del cuento hispanoamericano; selección, prólogo y notas de Mario Rodríguez Fernández. Santiago de Chile, Editorial Universitaria, 2006.

El dogma socialista, en http://www.cecies.org/imagenes/edicion_180.pdf. Visitado: 10 de abril del 2013. Echeverría Esteban. 
Ercilla, Alonso de. La Araucana. Madrid: Cátedra, 1993.

Nabokov, Vladimir. Curso de literatura europea. Barcelona: Zeta Bolsillo, 2009.

Neira Navarro, M. "Jeremy Bentham y el liberalismo en Chile durante la primera mitad del siglo XIX", en Boletín de la Academia Chilena de la Historia, $\mathrm{N}^{\circ} 113,2004: 285-313$.

Núñez de Pineda; Bascuñán, Francisco. Cautiverio Feliz, Edición crítica de Mario Ferreccio Podestá y Raissa Kordic Riquelme. Seminario de Filología Hispánica, Facultad de Filosofía y Humanidades, Universidad de Chile: Santiago, 2001.

Rodhe, Erwin. La novela griega y sus precursores (1876). Citado por: Carlos García Gual. 1972. Los orígenes de la novela. Ediciones Istmo: Madrid.

Rodríguez Freyle, Juan. El carnero. Ayacucho: Caracas, 1992.

Sarmiento, Domingo Faustino. Conflictos y armonías de las razas en América. La cultura Argentina: Buenos Aires, 1915.

Facundo. Ayacucho: Caracas, 2002. 